\title{
Comparison of pain and proper sample status according to usage of tenaculum and analgesia: a randomized clinical trial
}

\author{
Cihan Comba, MD', Gökhan Demirayak, MD², Sakir Volkan Erdogan, MD³ I Ibrahim Karaca, MD4, \\ Omer Demir, MD5, Oguz Guler, MD ${ }^{6}$, Isa Aykut Ozdemir, MD \\ Division of Gynecologic Oncology, Department of Gynecology and Obstetrics, ${ }^{1}$ University of Health Sciences, Sultangazi Haseki Training and Research \\ Hospital, Istanbul, ${ }^{2}$ University of Health Sciences, Bakirkoy Dr. Sadi Konuk Training and Research Hospital, Istanbul; Department of Gynecology and \\ Obstetrics, ${ }^{3}$ University of Health Sciences, Bagcilar Training and Research Hospital, Istanbul, ${ }^{4}$ University of Health Sciences, Tepecik Training and \\ Research Hospital, Izmir, ${ }^{5}$ Karadeniz Technical University, Trabzon, ${ }^{6}$ Kucukkoy Bilge Hospital, Istanbul; ${ }^{7}$ Division of Gynecologic Oncology, Department \\ of Gynecology and Obstetrics, Medipol University Mega Hospital, Istanbul, Turkey
}

\section{Objective}

Colposcopic biopsy is a discomfortable procedure. Additionally, it creates negative influence on sexuality. This study aimed to investigate the relationships among tenaculum, pain perception, and biopsy size during colposcopy.

\section{Methods}

In total, 228 patients who underwent colposcopy-directed biopsy were included, and randomized into 4 groups based on whether analgesic and tenaculum were used and replaced (tenaculum with $n=58 /$ without analgesic $n=56$, no tenaculum replacement with $n=57 /$ without analgesic $n=57)$. Lidocaine hydrochloride $(40 \mathrm{mg})$ plus adrenaline $(0.025$ $\mathrm{mg}$ ) was administered in the analgesic groups. The pain was assessed using a linear visual analog scale. The biopsy specimen size was measured in millimeters.

\section{Results}

The mean age of the patients was $42.85 \pm 8.88$ years. The most frequent colposcopy indications were atypical squamous cells of undetermined significance and human papilloma virus-positive results on cervical cytology (30.2\%; $n=69)$. Low- and high-grade intraepithelial lesions were noted in $14.91 \%(n=34)$ and $10.96 \%(n=25)$ women through colposcopy-directed biopsy results, respectively. Tenaculum replacement increased pain perception in the without analgesic group; however, no statistically significant differences were noted between of the groups with and without tenaculum replacement with analgesic. The size and number of biopsy specimens were not associated with tenaculum replacement and analgesic use.

\section{Conclusion}

Administration of analgesics decreased discomfort and pain in patients. Tenaculum replacement aided colposcopists in manipulating the cervix. Additionally, administration of analgesics relieved pain in the tenaculum replacement group.

\section{Trial Registration}

ClinicalTrials.gov Identifier: NCT03279666

Keywords: Cervix uteri; Biopsy; Pain perception; Human papilloma virus
Received: 2019.09.27. Revised: 2020.02.17. Accepted: 2020.02.18. Corresponding author: Cihan Comba, MD

Division of Gynecologic Oncology, Department of Gynecology and Obstetrics, University of Health Sciences, Sultangazi Haseki Training and Research Hospital, Uğur Mumcu, Hastane Cad No:1 A D:1B, 34265 Sultangazi/Istanbul, Turkey

E-mail: comba.cihan@yahoo.com.tr https://orcid.org/0000-0002-3161-2689

Articles published in Obstet Gynecol Sci are open-access, distributed under the terms of the Creative Commons Attribution Non-Commercial License (http://creativecommons org/licenses/by-nc/3.0/) which permits unrestricted non-commercial use, distribution, and reproduction in any medium, provided the original work is properly cited.

Copyright $\odot 2020$ Korean Society of Obstetrics and Gynecology 


\section{Obstetrics \& Gynecology Science}

Cihan Comba, et al. Suited technique for colposcopic biopsy

\section{Introduction}

Colposcopy is the cornerstone of cervical precancerous lesion evaluation [1]. It has been the standard of care for evaluating abnormal cervical cytology since the 1970s [2].

In conjunction with screening and treatment of precancerous lesions, colposcopy has played a crucial role in reducing the incidence and mortality due to cervical cancer for the past 50 years [1]. The current guidelines for initial management of high-grade cervical cytological abnormalities recommend an immediate diagnostic excisional procedure during the initial colposcopy that is critical to a "see-and-treat" approach in selected patients. In addition, it allows recognition of a subset of women with cervical disease and safe observation of the disease over time. Further, it plays an important role in reducing the over-treatment of low-grade lesions [3].

Procedure risks of colposcopy, such as significant bleeding, infection, and long-term morbidity, are low. Colposcopydirected punch biopsies are associated with discomfort, cramping, and pain. Furthermore, some women reported a negative influence on sexuality [4]. A traumatic colposcopy experience may lead to some women refraining from obtaining adequate cervical screening in the future [5]. Both abnormal cervical cytology results and colposcopy experience can induce anxiety in women [6]. A study reported that women experienced worry and anxiety in the interim period-the time between being notified of an abnormal screening result and colposcopy appointment [7]. However, the procedure can usually be performed on an outpatient basis without anesthesia [8]. Researchers have studied the use of local anesthesia, topical spray, and forced cough method to reduce pain due to colposcopy-directed punch biopsy [8-10], and most of these studies indicated that these methods were effective.

Most gynecologic oncology centers worldwide use the International Federation of Gynecology and Obstetrics staging system for gynecological cancers such as cervical cancer. The clinical stage is used for cervical cancer staging; hence, it is based on the results of the physical examination by doctor, biopsies, imaging tests, and a few other tests such as magnetic resonance imaging, cystoscopy, and proctoscopy [11]. Stage 1A (microinvasive) cervical cancer can only be detected through microscopic examination of removed tissue, preferably a cone; however, several punch biopsies may be required for diagnosis. Stage $1 \mathrm{~A}$ cervical cancer was defined as invasion limited to measured stromal invasion with a maximum depth of $5 \mathrm{~mm}$ and stage $1 \mathrm{~A} 1$ was defined as measured stromal invasion with a maximum depth of $3 \mathrm{~mm}$ [12]. Hence, punch biopsy size is crucial.

This study aimed to investigate the relationship among tenaculum placement, pain perception, and biopsy size during colposcopy.

\section{Materials and methods}

Bakirkoy Dr. Sadi Konuk Training and Research Hospital (BTRH), University of Health Sciences, was the reference center in the cervical smear and human papilloma virus (HPV) screening program for 30-65-year-old women. The screening had been performed by primary level health staff (family physicians and screening center staff) under the Republic of Turkey, Ministry of Health, since 2014. These centers referred women with high-risk (HR) HPV positive results to specific hospitals. HR-HPV detection was performed using the commercially available Hybrid Capture 2 assay ${ }^{\circledR}$ (HC2; Digene Corp., Gaithersburg, MD, USA). The results were assessed in BTRH, and colposcopy was performed by gynecologic oncology faculty members or gynecologic oncology fellows in patients with indications for colposcopy.

This study was conducted on patients with indications for colposcopy and within the scope of the Republic of Turkey, Ministry of Health Cervical Cancer Screening program between June 15, 2017 and December 31, 2017. The study was approved by the ethical board of BTRH (number: 2017/47) and was registered in ClinicalTrials.gov (number: NCT03279666). Informed consent was obtained from all the patients before the procedure. Patients were randomized using a computer program. A statistical program (GPower version 3, Heinrich Heine University, Düsseldorf, Germany) was used to estimate the sample size through a 1-tailed hypothesis using an independent sample t-test with an a error of 0.05 and a power of 0.90 . The total sample size required for a moderate effect size $(d=0.50)$ was calculated to be 236. In the present study, 58 women were in group $A, 56$ women were in group B, 57 women were in group $C$, and 57 women were in group D. Post hoc analysis for moderate effect size indicated that the power of the test was reduced to 0.80 . In addition to undergoing colposcopy, the inclusion criteria for the study were as follows:

- Being older than 21 years old 


\section{Obstetrics \& Gynecology Science}

Vol. 63, No. 4, 2020

- No history of receiving colposcopy, loop electrosurgical excision procedure (LEEP), conization, or cryotherapy

- Did not use analgesics up to 6 hours before the procedure

- Did not experience chronic pain or did not use analgesics for a long-term

- Did not have advanced atrophic or hypertrophic cervix

- Did not have visible cervical mass (polyp, myoma, or locally advanced cervical cancer)

The exclusion criteria were as follows:

- Did not provide consent for participation in the study

- Had advanced orthopedic problem

- Had allergy to analgesics

- Were pregnant

This study enrolled 228 women. Patients were randomly assigned to 4 groups (Fig. 1).

- Group 1: patients with tenaculum replacement without analgesic $(n=58)$

- Group 2: patients without tenaculum replacement with- out analgesic $(n=56)$

- Group 3: patients with tenaculum replacement with analgesic $(n=57)$

- Group 4: patients without tenaculum replacement with analgesic $(n=57)$

The number of patients who underwent cervical biopsy as well as endocervical curettage (ECC), only cervical biopsy, and only ECC were 182, 42, and 4, respectively.

The patients were placed in the lithotomy position in a quiet colposcopy room and using a single-use vaginal speculum colposcopy was performed by the gynecologic oncology team, comprising a doctor and nurse. Colposcopy was started by cleaning the cervix with $5-\mathrm{mL}$ saline. Cotton soaked in freshly prepared $5 \%$ acetic acid solution was applied on the cervix for 3 minutes, and subsequently, colposcopic examination was performed. Then, 2-mL lidocaine hydrochloride (40 $\mathrm{mg}$ ) plus adrenaline $(0.025 \mathrm{mg}$ ) was injected at the 8 and 4 o'clock positions of the cervix using a 22-gauge needle to
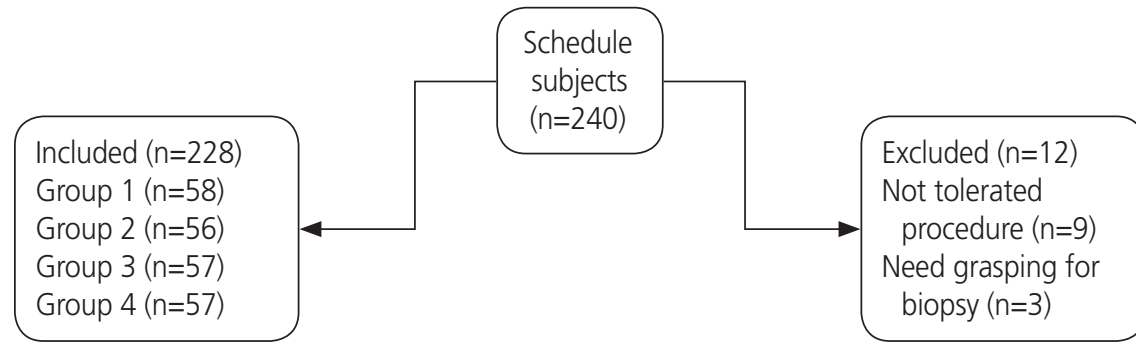

Fig. 1. Flow diagram of the study.

Table 1. General data of all groups

\begin{tabular}{|c|c|c|c|c|c|}
\hline Variables & Group $1(n=58)$ & Group $2(n=56)$ & Group $3(n=57)$ & Group $4(n=57)$ & $P$-value ${ }^{\text {a) }}$ \\
\hline Gravidy & $4.57 \pm 4.9 / 3(0-34)$ & $3.2 \pm 1.9 / 3(0-9)$ & $3.1 \pm 1.9 / 3(0-9)$ & $3.6 \pm 2.6 / 3(0-14)$ & 0.327 \\
\hline Parity & $3.02 \pm 2.06 / 2(0-12)$ & $2.7 \pm 1.8 / 2(0-8)$ & $2.3 \pm 1.4 / 2(0-7)$ & $2.4 \pm 1.5 / 2(0-7)$ & 0.297 \\
\hline SVD & $2.6 \pm 2.2 / 2(0-12)$ & $2.1 \pm 1.9 / 2(0-7)$ & $1.9 \pm 1.6 / 2(0-7)$ & $2.02 \pm 1.7 / 2(0-7)$ & 0.540 \\
\hline SCA & $0.5 \pm 0.9 / 0(0-4)$ & $0.46 \pm 0.8 / 0(0-3)$ & $0.35 \pm 0.7 / 0(0-3)$ & $0.3 \pm 0.6 / 0(0-3)$ & 0.681 \\
\hline Abortus & $0.69 \pm 1.4 / 0(0-9)$ & $0.38 \pm 0.6 / 0(0-2)$ & $0.54 \pm 0.7 / 0(0-3)$ & $0.89 \pm 1.2 / 0(0-5)$ & 0.099 \\
\hline UC & $0.88 \pm 3.9 / 0(0-30)$ & $0.13 \pm 0.5 / 0(0-2)$ & $0.21 \pm 0.8 / 0(0-5)$ & $0.28 \pm 0.9 / 0(0-5)$ & 0.112 \\
\hline Age & $43.4 \pm 10.03 / 42(28-72)$ & $43.1 \pm 8.5 / 42.5(29-64)$ & $41.8 \pm 7.9 / 41(27-60)$ & $43.1 \pm 9.1 / 44(25-63)$ & 0.809 \\
\hline Number of biopsy & $2.9 \pm 1.04 / 3(1-5)$ & $3.3 \pm 1.2 / 3(1-5)$ & $3.6 \pm 0.9 / 3(1-6)$ & $3.7 \pm 0.9 / 4(2-6)$ & $0.001^{b)}$ \\
\hline Pain level & $3.9 \pm 3.1 / 3(0-10)$ & $4 \pm 3.3 / 3(0-10)$ & $2.2 \pm 2.7 / 1(0-10)$ & $2.6 \pm 3.02 / 1(0-10)$ & $<0.001^{\mathrm{b})}$ \\
\hline Size of biopsy_median & $3.4 \pm 1.3 / 3.3(1-8)$ & $3.8 \pm 1.8 / 3.5(1-8.3)$ & $3.6 \pm 1.2 / 3.3(1.7-7.5)$ & $3.7 \pm 1.3 / 3.7(1-7)$ & 0.492 \\
\hline
\end{tabular}

Values are presented as mean \pm standard deviation/median (minimum-maximum). Group 1, patients with tenaculum replacement without analgesic; Group 2, patients without tenaculum replacement without analgesic; Group 3, patients with tenaculum replacement with analgesic; Group 4, patients without tenaculum replacement with analgesic.

SVD, spontaneous vaginal delivery; SCA, sectio caserean abdominalis; UC, uterine curuttage for unwanted pregnancy.

${ }^{\text {a)}}$ Kruskal-Wallis test; ${ }^{b} P<0.01$. 


\section{Obstetrics \& Gynecology Science}

Cihan Comba, et al. Suited technique for colposcopic biopsy

those in the groups 3 and 4 . The doctor waited for 2 minutes for the analgesic to take effect before obtaining biopsy specimens. Biopsy specimens were obtained from necessary sites by using a biopsy equipment (Schumacher biopsy forceps 1/1 made in Germany), with or without tenaculum replacement on the anterior part of the cervix transversely in accordance with the group. ECC was performed using a Recamier uterine curette (width $3 \mathrm{~mm}$ made in Germany) if required. Subsequently, the linear visual analog scale was used to assess pain within 2 minutes after colposcopic examination.

\section{Statistical analysis}

Descriptive statistics were used to define continuous variables (mean; standard deviation; and minimum, median, and maximum). The Kruskal-Wallis test was used to analyze the association between more than 2 continuous variables that were independent and not normally distributed. The Mann-Whitney $U$ test was used to analyze the association between 2 continuous variables that were independent and not normally distributed. The correlation between 2 continuous variables without normal distribution was analyzed with Spearman's rho correlation analysis. Chi-square (or Fisher exact test as applicable) was used to analyze the association between categorical variables. Statistical significance was set at $P=0.05$. The analyses were conducted using MedCalc Statistical Software version 12.7.7 (MedCalc Software bvba, Ostend, Belgium; http://www.medcalc.org; 2013).

\section{Results}

A total of 228 of 240 patients were analyzed. Ten patients were excluded because they did not provide consent to participate and other 2 patients were excluded because their biopsy results indicated cervical cancer. The mean age of included patients was $42.85 \pm 8.88$ years (range, $25-72$ years; Table 1). The most frequent colposcopy indications were atypical squamous cells of undetermined significance and HPV positive results on cervical cytology ( $n=69 ; 30.2 \%)$. The most common HR-HPV type was HPV 16 ( $n=68 ; 29.8 \%$ ). HPV 51 was the most frequently detected non-HPV 16-18 of the high-risk HPV types (Table 2). Normal cytology, low-grade intraepithelial lesions and high-grade intraepithelial lesions

Table 3. Relationship between pathological results and pain perception

\begin{tabular}{|c|c|}
\hline Pathological result & Pain perception \\
\hline \multicolumn{2}{|c|}{ Pathological result of ECC } \\
\hline Inadequate $(n=11)$ & $3.4 \pm 2.6 / 2(1-9)$ \\
\hline Normal $(n=162)$ & $2.9 \pm 3.1 / 1(0-10)$ \\
\hline $\operatorname{LSIL}(n=6)$ & $4.7 \pm 3.7 / 4(1-10)$ \\
\hline $\mathrm{HSIL}(n=7)$ & $4 \pm 3.4 / 2(0-9)$ \\
\hline$P$-value ${ }^{a}$ & 0.277 \\
\hline \multicolumn{2}{|c|}{ Pathological result of biopsy } \\
\hline Normal $(n=164)$ & $3.1 \pm 3.1 / 2(0-10)$ \\
\hline LSIL $(n=34)$ & $3.7 \pm 3.5 / 2.5(0-10)$ \\
\hline HSIL (n=25) & $3.1 \pm 3.03 / 2(0-10)$ \\
\hline Cancer $(n=1)$ & - \\
\hline$P$-value ${ }^{\text {a) }}$ & 0.653 \\
\hline \multicolumn{2}{|c|}{$\begin{array}{l}\text { Values are presented as mean } \pm \text { standard deviation/median (min } \\
\text { mum-maximum). } \\
\text { ECC, endo cervical curettage; LSIL, low grade intraepithelial lesion } \\
\text { HSIL, high grade intraepithelial lesion. } \\
\text { a) Kruskal-Wallis test. }\end{array}$} \\
\hline
\end{tabular}

Table 2. Human papilloma virus status

\begin{tabular}{|c|c|c|c|c|c|}
\hline HPV type & Group $1(n=58)$ & Group $2(n=56)$ & Group $3(n=57)$ & Group $4(n=57)$ & $P$-value \\
\hline Negative & $16(27.6)$ & $15(27.3)$ & $24(42.1)$ & $24(42.1)$ & 0.044 \\
\hline HPV type 16 & $13(22.4)$ & $10(18.2)$ & $14(24.6)$ & $8(14.0)$ & \\
\hline HPV type 18 & $2(3.4)$ & $2(3.6)$ & $3(5.3)$ & $2(3.5)$ & \\
\hline HPV type $16+18$ & $6(10.3)$ & $8(14.5)$ & $3(5.3)$ & $2(3.5)$ & \\
\hline HPV type non 16-18 & $15(25.9)$ & $19(34.5)$ & $8(14.0)$ & $10(17.5)$ & \\
\hline HPV type 16 or $18+$ HPV-N & $6(10.3)$ & $1(1.8)$ & $5(8.8)$ & $11(19.3)$ & \\
\hline
\end{tabular}

Values are presented as number (\%). Hybrid capture 2 technology was used for detection of 13 high-risk HPV types. HPV, human papilloma virus; HPV-N, non 16-18 high-risk HPV types.

${ }^{a)}$ Ki-Kare test. 


\title{
Obstetrics \& Gynecology Science
}

\author{
Vol. 63, No. 4, 2020
}

(HSIL) were noted in $73.68 \%(n=168), 14.91 \%(n=34)$, and $10.96 \%$ ( $n=25$ ) women, respectively. Squamous cell cervical cancer was noted in one patient with HSIL who underwent conization (Table 3).

On the basis of post hoc paired comparisons, statistically significant differences were observed between groups 1 and 3 and between groups 1 and 4 for the distribution of biopsy count (Mann-Whitney $U, P<0.05$, Bonferroni correction). Group 1 had a lower mean for biopsy counts. The mean biopsy size did not differ between groups (Table 4).

Statistically significant differences were observed between groups 1 and, between groups 1 and 4, between groups 2 and 3 , and between groups 2 and 4 for pain perception (Mann-Whitney $U, P<0.05$, Bonferroni correction). In groups 1 and 2, the mean level of pain was higher than that in the groups 3 and 4 . Although few biopsy specimens were obtained in group 1, pain severity in group 1 was higher than that in groups administered with lidocaine hydrochloride (40 mg) plus adrenaline (0.025 mg; Table 5).

The pain was statistically higher among patients who underwent cesarean section once, who did not undergo curettage, and who were nulliparous. Menopause, smoking

Table 4. Post hoc binary comparison between number of biopsy and pain perception

\begin{tabular}{lcc}
\hline $\begin{array}{c}\text { Post hoc binary } \\
\text { comparison }\end{array}$ & $\begin{array}{c}\text { Number of } \\
\text { biopsy }^{\text {a) }}\end{array}$ & $\begin{array}{c}\text { Pain } \\
\text { perception }^{\text {a) }}\end{array}$ \\
\hline Group 1 vs. Group 2 & 0.131 & 0.975 \\
Group 1 vs. Group 3 & $0.001^{\text {b) }}$ & $<0.001^{\text {b) }}$ \\
Group 1 vs. Group 4 & $<0.001^{\text {b) }}$ & $0.004^{\text {b) }}$ \\
Group 2 vs. Group 3 & 0.135 & $0.001^{\text {b) }}$ \\
Group 2 vs. Group 4 & 0.054 & $0.007^{\text {b) }}$ \\
Group 3 vs. Group 4 & 0.495 & 0.679 \\
\hline
\end{tabular}

a) Mann-Whitney $U$ test; ${ }^{b} P<0.01$. and alcohol consumption, educational degree, presence of chronic illness, pathological results of cervical smear, presence of HPV, ECC, and pathological results of ECC and biopsy did not have an influence on pain perception. However, pain perception differed among groups with 3 or 5 biopsy specimens (Kruskal-Wallis, $P<0.05$ ). Paired comparisons data indicated that pain perception in group 1 was higher than that in groups 3 and 4, wherein 3 biopsy specimens were obtained from patients, and that in group 2 was higher than that in group 3, wherein 5 biopsy specimens were obtained from patients (Mann-Whitney $U, P<0.05$ ). In all the groups, no statistically significant difference was noted in biopsy size and pain (Spearman's rho, P>0.05), and the sizes of the biopsy specimens were $>3 \mathrm{~mm}, 3 \mathrm{~mm}$ tumoral tissue which is considered a stage $1 \mathrm{~A} 1$-stage $1 \mathrm{~A} 2$ threshold for cervical cancer.

Although pain during colposcopic biopsy was not severe, administration of the analgesic decreased discomfort and pain in patients, resulting in better cervical assessment with colposcopy. Although tenaculum placement increased pain perception mildly, it aided colposcopists to manipulate the cervix and obtain biopsy specimens easily. In addition, administration of analgesics relieved pain in patients of the tenaculum replacement group, without any influence on the biopsy size.

\section{Discussion}

Colposcopy and related procedures have been recognized to be potentially painful [13]. Women experiencing pain during colposcopy are anxious, and interventions aimed at reducing the level of pain and anxiety before and during colposcopy are useful [14]. Studies have reported that anxiety levels be-

Table 5. Correlation between number of biopsy and pain level

\begin{tabular}{|c|c|c|c|c|c|c|}
\hline $\begin{array}{c}\text { Number of } \\
\text { biopsy }\end{array}$ & $1(n=21)$ & $2(n=45)$ & $3(n=42)$ & $4(n=59)$ & $5(n=61)$ & $P$-value ${ }^{\text {a) }}$ \\
\hline Group 1 & $4 \pm 3.3 / 3(0-9)$ & $3.1 \pm 2.9 / 1.5(0-9)$ & $4.2 \pm 2.8 / 4(1-10)$ & $4.3 \pm 3.5 / 3(0-10)$ & $4.3 \pm 4.9 / 2(1-10)$ & 0.588 \\
\hline Group 2 & $4.3 \pm 4.5 / 4(0-9)$ & $3.1 \pm 3.03 / 1(0-10)$ & $3.1 \pm 2.9 / 2(0-10)$ & $6.1 \pm 2.8 / 6.5(1-10)$ & $4.4 \pm 3.5 / 3(0-10)$ & 0.151 \\
\hline Group 3 & - & $1.2 \pm 0.9 / 1.5(0-2)$ & $2.2 \pm 2.8 / 1(0-10)$ & $3.1 \pm 3.1 / 1.5(0-10)$ & $0.7 \pm 1.4 / 0(0-4)$ & 0.065 \\
\hline Group 4 & - & $3 \pm 3.3 / 2.5(0-7)$ & $1.8 \pm 3.1 / 1(0-10)$ & $3.3 \pm 3.1 / 2(0-10)$ & $2.4 \pm 2.8 / 1(0-8)$ & 0.344 \\
\hline$P$-value ${ }^{\text {a) }}$ & 0.830 & 0.757 & $0.002^{c)}$ & 0.078 & $0.019^{b)}$ & - \\
\hline
\end{tabular}

Values are presented as mean \pm standard deviation/median (minimum-maximum).

${ }^{\text {a) }}$ Kruskal-Wallis test; ${ }^{\text {b) }} P<0.05 ;{ }^{c} P<0.01$. 


\section{Obstetrics \& Gynecology Science}

Cihan Comba, et al. Suited technique for colposcopic biopsy

fore and during the procedure are elevated in women. Particularly, anxiety can be attributed to the uncertainty regarding what the colposcopic examination entails, events during the procedure, and fear or experience of pain during the procedure $[15,16]$. Humor, imagination of pleasant scenes and experiences, music, and forced coughing have been reported to reduce pain through the gate control theory of pain based on partial inhibition of painful sensations traveling along slower nerve fibers by overriding stimuli that travel along fast nerve fibers $[17,18]$. However, to the best of our knowledge, no study has reported the relationship among the use of tenaculum, pain perception, and biopsy size to date.

In 2011, Naki et al. [10] found that local anesthesia was more effective than forced coughing for relieving pain during cervical biopsy, in contrast to Schmid et al. [9] in 2008, but the duration of the entire procedure was significantly longer in patients in the local anesthetic group [10].

Bogani et al. [19] observed that nulliparity, number of previous vaginal deliveries, and pain expectancy were associated with pain perception during colposcopic biopsy, and only pain expectancy independently correlated with operative pain levels. Factors such as educational level, obstetric history, and chronic pelvic pain may affect the anticipated pain score. Öz et al. [20] reported a significantly inverse relationship between patients' educational level and reported pain scores after both cervical biopsy and ECC procedures. On the contrary, in the present study, we found that women who were nulliparous, who underwent cesarean section abdominalis, and who did not undergo dilatation and curettage perceived a higher level of pain. However, education, menopause, smoking, history of ECC, and chronic diseases were found to be not associated with pain score.

The first study by Rabin et al. [21] investigated the use of local anesthesia for gynecological procedures by comparing $20 \%$ benzocaine gel with placebo for its ability to reduce pain associated with cervical biopsy, intrauterine device insertion, pain associated with injection of anesthetic drug, tenaculum placement, and ECC, and revealed that $20 \%$ benzocaine gel significantly reduced pain associated with these procedures. In the current study, it was found that local anesthesia reduced pain perception as a significant difference in pain perception was noted between the groups without tenaculum replacement and with or without local anesthesia.

Several scientific studies have indicated that women subjected to a passive, pleasing and simple visual distraction dur- ing colposcopy experienced less post procedural pain than those who were not subjected to visual distraction $[22,23]$. In the present study, the overall pain level in group 3 patients was low $(2.2 \pm 2.7)$.

The procedure type may affect patients' pain perception. Kola-Palmer et al. [24] reported that a significant difference in sensory pain existed between treatment groups of women undergoing see-and-treat large loop excision of the transformation zone treatment and those undergoing colposcopy plus punch biopsy who reported significantly higher levels of pain perception than women who underwent diagnostic colposcopy.

The tenaculum is used to stabilize and supply counter traction on the cervix and uterus [25]. A study by Goldthwaite et al. [26] compared pain scores with tenaculum placement after injecting intracervical lidocaine and topically applying lidocaine gel. Lidocaine injection was more effective than lidocaine gel application in the study. Robinson et al. [27] indicated that a significant difference in pain perception existed after comparing intracervical lidocaine injection (saline injection), when traction was placed with tenaculum during hysterosalpingography, with no injection. Oyama et al. [28] revealed that lidocaine injection reduced pain score during cervical biopsies and endocervical curettage, and overall procedure scores. Additionally, Kiviharju et al. [29] found that local anesthesia decreased the pain sensation. In the present study, we found that intracervical lidocaine injection reduced pain during colposcopic biopsy.

Colposcopists speculate that the most suitable colposcopic assessment and biopsy method is the one that involves administration of analgesics and tenaculum use (group 3 in this study). This method can aid in reducing pain, and the physician can manipulate the cervix and obtain biopsy specimens easily during the procedure. Invasive cancer can be diagnosed with a single biopsy. However, generally, biopsy instruments are not sufficiently large to diagnose invasive cancer. In addition, further studies with more participants should be conducted to investigate whether the size of the biopsy specimen has an influence.

\section{Conflict of interest}

No potential conflict of interest relevant to this article was reported. 


\section{Obstetrics \& Gynecology Science}

Vol. 63, No. 4, 2020

\section{Ethical approval}

All the procedures performed in the study were in accordance with the ethical standards of the institutional and/ or national research committee and with the 1964 Helsinki declaration and its later amendments or comparable ethical standards.

\section{Patient consent}

Informed consent was obtained from all the study participants.

\section{References}

1. King A, Clay K, Felmar E, Heustis DG, Karns RM, Krahl P, et al. The Papanicolaou smear. West J Med 1992;156:202-4.

2. Singer A, Walker P, Tay SK, Dyson J. Impact of introduction of colposcopy to a district general hospital. Br Med J (Clin Res Ed) 1984;289:1049-51.

3. Massad LS, Einstein MH, Huh WK, Katki HA, Kinney WK, Schiffman M, et al. 2012 updated consensus guidelines for the management of abnormal cervical cancer screening tests and cancer precursors. Obstet Gynecol 2013;121:829-46.

4. Campion MJ, Brown JR, McCance DJ, Atia W, Edwards $\mathrm{R}$, Cuzick J, et al. Psychosexual trauma of an abnormal cervical smear. Br J Obstet Gynaecol 1988;95:175-81.

5. Ideström M, Milsom I, Andersson-Ellström A. Women's experience of coping with a positive Pap smear: a register-based study of women with two consecutive Pap smears reported as CIN 1. Acta Obstet Gynecol Scand 2003;82:756-61.

6. Kola-Palmer S, Walsh JC. Correlates of psychological distress immediately following colposcopy. Psychooncology 2015;24:819-24.

7. Waller J, McCaffery K, Kitchener H, Nazroo J, Wardle J. Women's experiences of repeated HPV testing in the context of cervical cancer screening: a qualitative study. Psychooncology 2007;16:196-204.

8. Clifton PA, Shaughnessy AF, Andrews S. Ineffectiveness of topical benzocaine spray during colposcopy. J Fam
Pract 1998;46:242-6.

9. Schmid BC, Pils S, Heinze G, Hefler L, Reinthaller A, Speiser P. Forced coughing versus local anesthesia and pain associated with cervical biopsy: a randomized trial. Am J Obstet Gynecol 2008;199:641.e1-3.

10. Naki MM, Api O, Acioglu HC, Uzun MG, Kars B, Unal $O$. Analgesic efficacy of forced coughing versus local anesthesia during cervical punch biopsy. Gynecol Obstet Invest 2011;72:5-9.

11. Freeman SJ, Aly AM, Kataoka MY, Addley HC, Reinhold C, Sala E. The revised FIGO staging system for uterine malignancies: implications for MR imaging. Radiographics 2012;32:1805-27.

12. Bhatla N, Aoki D, Sharma DN, Sankaranarayanan R. Cancer of the cervix uteri. Int I Gynaecol Obstet 2018;143 Suppl 2:22-36.

13. Gajjar K, Martin-Hirsch PP, Bryant A. Pain relief for women with cervical intraepithelial neoplasia undergoing colposcopy treatment. Cochrane Database Syst Rev 2012;10:CD006120.

14. Hilal Z, Alici F, Tempfer CB, Seebacher V, Rezniczek GA. Video colposcopy for reducing patient anxiety during colposcopy a randomized controlled trial. Obstet Gynecol 2017; 130:411-9.

15. Galaal K, Bryant A, Deane KH, Al-Khaduri M, Lopes $A D$. Interventions for reducing anxiety in women undergoing colposcopy. Cochrane Database Syst Rev 2011;7:CD006013.

16. Bosgraaf RP, de Jager WC, Servaes P, Prins JB, Massuger $L F$, Bekkers RL. Qualitative insights into the psychological stress before and during colposcopy: a focus group study. J Psychosom Obstet Gynaecol 2013;34:150-6.

17. Tsao JC, Fanurik D, Zeltzer LK. Long-term effects of a brief distraction intervention on children's laboratory pain reactivity. Behav Modif 2003;27:217-32.

18. Dickenson $\mathrm{AH}$. Gate control theory of pain stands the test of time. Br J Anaesth 2002;88:755-7.

19. Bogani G, Serati M, Cromi A, Di Naro E, Casarin J, Pinelli $C$, et al. Local anesthetic versus forced coughing at colposcopic-guided biopsy: a prospective study. Eur J Obstet Gynecol Reprod Biol 2014;181:15-9.

20. Öz M, Korkmaz E, Cetinkaya N, Baş S, Özdal B, Meydanl $M M$, et al. Comparison of topical lidocaine spray with placebo for pain relief in colposcopic procedures: a randomized, placebo-controlled, double-blind study. J Low 


\section{Obstetrics \& Gynecology Science}

Cihan Comba, et al. Suited technique for colposcopic biopsy

Genit Tract Dis 2015;19:212-4.

21. Rabin JM, Spitzer M, Dwyer AT, Kaiser IH. Topical anesthesia for gynecologic procedures. Obstet Gynecol 1989;73:1040-4.

22. Chan YM, Lee PW, Ng TY, Ngan HY, Wong LC. The use of music to reduce anxiety for patients undergoing colposcopy: a randomized trial. Gynecol Oncol 2003;91:213-7.

23. Walsh JC, Curtis R, Mylotte M. Anxiety levels in women attending a colposcopy clinic: a randomised trial of an educational intervention using video colposcopy. Patient Educ Couns 2004;55:247-51.

24. Kola-Palmer S, Walsh JC, Rogers M. Patients' perceptions of colposcopy pain. Eur J Cancer Care (Engl) 2016;25:49-56.

25. Johnson N, Bromham DR. Effect of cervical traction with a tenaculum on the uterocervical angle. Br J Obstet Gyn- aecol 1991;98:309-12.

26. Goldthwaite LM, Baldwin MK, Page J, Micks EA, Nichols $M D$, Edelman $A B$, et al. Comparison of interventions for pain control with tenaculum placement: a randomized clinical trial. Contraception 2014;89:229-33.

27. Robinson RD, Casablanca Y, Pagano KE, Arthur NA, Bates GW, Propst AM. Intracervical block and pain perception during the performance of a hysterosalpingogram: a randomized controlled trial. Obstet Gynecol 2007;109:89-93.

28. Oyama IA, Wakabayashi MT, Frattarelli LC, Kessel B. Local anesthetic reduces the pain of colposcopic biopsies: a randomized trial. Am J Obstet Gynecol 2003;188:1164-5.

29. Kiviharju M, Kalliala I, Nieminen P, Dyba T, Riska A, Jakobsson M. Pain sensation during colposcopy and cervical biopsy, with or without local anesthesia: a randomized trial. J Low Genit Tract Dis 2017;21:102-7. 